\title{
Zoltàn Kövecses, Extended Conceptual Metaphor Theory. Cambridge: Cambridge University Press, 2020.
}

\section{Elżbieta Tabakowska}

Uniwersytet Jagielloński w Krakowie

elzbieta.tabakowska@gmail.com

On the cover, the title of Zoltàn Kövecses's newest book Extended Conceptual Metaphor Theory (ECMT) has been printed against the colourful background picture of a cherry tree in full blossom. This metonymic image of spring evokes a metaphor that seems very appropriate. Although some of the material presented in the ECMT had been published in Kövecses's earlier books and articles, most of the contents of his recent monograph have been either significantly extended or discussed within an overall framework which presents the theory as a comprehensive and coherent construct. But there seems to be more to the cherry blossom metaphor: on the cover, individual branches, which are separate at the bottom, meet at the top, just as elements of standard conceptual metaphor theory meet and intertwin within the proposed framework of ECMT.

The book consists of eight chapters, preceded by a List of Figures, a List of Tables and a Preface, and followed by References and an Index. The table of contents reflects the overall structure of the monograph: clear, transparent, logical. Like in earlier publications by Zoltàn Köveces, an obvious asset of this one is the way in which notions and ideas - often complex and difficult - are presented to the reader. To borrow an expression from the adjacent discipline of literary studies, this new book reads well. Extremely well.

As the author states in the Preface, the birth of a metaphor is an extremely complicated cognitive event, which can only be fully understood if one decides to go beyond the limits set by standard theories. And this is precisely what the author does. Over the years that have passed since Conceptual Metaphor Theory (CMT) was first proposed, it has developed into a general comprehensive framework. While Kövecses believes that CMT provides effective instruments for metaphor explanation and description, he also claims that the theory should be extended to incorporate aspects that have not been adequately provided for. 
Individual chapters of the monograph correspond to several propositions that the author puts forward. Chapter 1 brings an outline of CMT. It is generally assumed (following Lakoff \& Johnson 1980) that conceptual metaphor results from understanding one domain of experience (typically abstract) in terms of another (typically concrete); thus it is only natural to believe that it can be considered as either process or product. Kövecses proposes to disregard the distinction (2020: 1) - a decision that might seem questionable, also in view of some of the points brought up in further discussion. In the course of the chapter the author offers a survey of the main features of CMT, the most important of which, with regard to the following chapters, are the ubiquity of metaphor, the process of cross-domain mapping (it is at this point that the author introduces his postulate that Conceptual Integration Theory (CIT) should be considered a stage in the process of metaphorization), the constraints on and conditions of mappings, and - perhaps most crucially - the relations between metaphors and ICM's as well as the role of context in metaphorization. Kövecses modifies the term "network" (usually used in the literature with reference to "network models" of conceptual integration and metaphor formation) and then applies it to a set of five principles that underlie the structurisation of metaphorical mappings within organized systems of metaphors. Each principle is illustrated with examples based upon, or taken from, contemporary everyday English. The most important principle involves "straightforward hierarchies", that is, mappings between "specific-level concepts of generic-level conceptual metaphors" (2020: 12). Frequent and relatively simple, this particular network is constitutive of the ECMT, as proposed further in the book. The principle of hierarchical organization, fundamental for the ECMT presented in the monograph, underlies yet another network: the organisation of target concepts, whereby entities on one level are conceptualized as entities on another level, as, e.g. in PEOPLE ARE ANIMALS (2020: 16).

Further in the chapter the author offers a critique of CMT, raised both in the relevant literature and in his own writings. Main criticism involves lack of precision in the researchers' attempts to define the crucial concept of "(cognitive) domain" and the circularity of reasoning when identifying conceptual - as opposed to linguistic - metaphors. The claim that at least some of such shortcomings could be overcome if more attention was paid to social and pragmatic dimensions of discourse parallels the majority of the postulates put forward in recent research on metaphor (cf. e.g. Navarro i Ferrando 2019). Most importantly, Kövecses claims that a more comprehensive approach would make it possible for the researchers to fulfil what he calls their "mission", that is, to describe various aspects of "behaviour and function of the 
metaphors in real data" (2020: 18). Further chapters mark consecutive steps taken in that direction.

The chapter ends with a long list of as many as thirteen questions that justify the need of extending CMT. The questions deal with the most pertinent problems that contemporary research on metaphor must face. They involve the methodically difficult distinction between literal and figurative meaning, possible emergence of primary metaphors via metonymy, problems involved in establishing the level of identification of conceptual metaphors, the significance of individual metaphor networks, socio-pragmatic functions of metaphor in discourse, the pertinent question whether the processes of metaphorization work in an ad hoc way rather than reside in conceptual systems which are stored in long term memory, and the possibility to integrate the process of metaphor production into CMT. The chapter ends with several significant questions: how to go beyond the limited - and inadequate - account of factors operative in novel metaphor production, how to account for mixed metaphors and their prevalence over homogeneous discourse, and what types of metaphor other than conceptual can be identified and, finally, how are these two categories related.

It might seem that more questions are asked than answered, but the consecutive chapters of the book warrant optimism. Thus in chapter two Köveces asks a provocative question: if the abstract can be understood figuratively and the concrete can be understood literally, is it possible to attach figurative understanding to the concrete? He argues that even the most basic concrete experiences can be conceptualized figuratively, and literal meaning need not always be considered basic. This assumption brings him to the moot point of contemporary theories of metaphor: defining the limits of literalness. As he shows further in the book, the classical criterion, i.e. one domain for the literal and multiple domains for the figurative, leaks, since precise delimitation is impossible by definition; at this point, the reader might probably think about the encyclopaedic character of meaning. Further in the chapter, Kövecses argues that much of what is today understood in metaphorical terms used to be concrete in the past (viz. the etymology of the Greek idea), while etymological study reveals that many concrete concepts have resulted from metonymies or metaphors (viz. English "book" from protoGermanic *bokiz, "birch", on whose bark early texts were written). What follows, is a fairly radical hypothesis: "the literal" does exist, but there is less of it than might seem (to linguists): "literalness" embraces, almost exclusively, such concepts as basic level things and events, spatial relations, body parts and basic emotions (2020: 28). The crux of the argument is that a literal concept can become subject to figurative construction of experience. As illustration, Köveces offers the concept of smell, which is construed along three conceptual dimensions: 
existence (smell is a substance in a container), intensity (strong vs. weak: smell is a physical force), and lack of control (smell is something that the experiencer "cannot help perceiving"; 2020: 29). The first dimension involves literal conceptualization, the second one is conceptualized figuratively, and the third may be conceptualized either literally or metaphorically. It seems, however, that the dimension of (lack of) control can be questioned, especially with reference to languages other than English. For instance, Polish distinguishes between the "no control" smelling, as in pachnieć ("ten wełniany płaszcz pachnie naftaliną", this woollen coat smells of mothballs), or czuć zapach ( "czujesz dym?", do you smell smoke?), and the "in control" smelling, as in wąchać ("lubiłem wąchać jej włosy", which the reverso.net corpus renders as I just liked smellin' her hair). Interestingly, unlike in the case of the "no control" conceptualizations, the aspect of volition does not extend over figurative meanings. An analysis that would make a principled distinction between conceptual metaphors considered as either processes or products (intentionally left out of ECMT, cf. above) might help further refine the theory.

The chapter concludes with a pertinent analogy: parallel to Langacker's fundamental distinction between contents and construal, Kövecses proposes that both concrete and abstract concepts be treated as having "both embodied content ontology and figurative construal (i.e. figuratively constructed understanding) - but in different proportions" (2020: 33).

The postulate tallies with the argument presented in chapter 3 , which deals with the emergence of metaphor. The question that the author poses at this point is whether metonymy could be considered an intermediate stage in the process through which metaphors emerge. He claims that this mediation is operative in correlation-based metaphors - the claim that is substantiated further in the body of the chapter. He addresses the perennial problem that research on metaphor must inevitably face: what are the criteria that make it possible to decide whether mappings occur within one domain or across two (or more) domains. The difficulty in finding an operational answer results in "the difficulty concerning whether particular expressions are metaphoric or metonymic" (2020:36). To solve the problem, Kövecses claims that (correlation-based) metaphors can be derived from metonymies; two mechanisms at work in the process are generalization and specialization (which correspond to schematization and elaboration in Langacker's model of language). Metaphor emerges when "the initial frame is conceptualized in terms of another, conceptually distant frame, or domain" (2020: 35), with the "distance" implying a "different taxonomic hierarchy" (2020: 39). While the description of the process seems very convincing, the main question remains: what makes us think that in a 
given case "one element is moved out of the initial frame to establish a new and independent frame"? (2020: 49).

It is worth noticing that in chapter 3 the notions of "domain" and "frame" are considered as synonymous - a terminological, and notional, levelling which the author refutes in the following chapter, ch. 4., where he takes up the terminological, or notional, problem of distinguishing between domains, schemas, frames and (mental) spaces. He rightly attributes the terminological chaos to the extreme complexity of the subject matter, however, further complicating the issue by adding to the set the term "scenario". He proposes to use these terms to refer to conceptual structures occurring at different levels of schematicity, thus representing a hierarchy of systems of notions - covering areas which are distinct, but lacking sharp borders. The relation between the structures is that of inclusion. The main body of the chapter presents a set of definitions, which serve as the foundation for theoretical claims made further in the book. Proposals offered in earlier research are supplemented and extended to give a set of definitions whose clarity and logical structuring make them a perfect reference chapter for anyone working, or intending to work, in the field.

In further sections of the chapter the proposed hierarchy of conceptual structures is used to expound what Kövecses calls the "multilevel view of conceptual metaphor": it operates on the level of domains, out of which certain frames are chosen and then specified by selections made out of particular metal spaces. The presentation of the relation between the type of metaphor and the way it is stored in memory and used, when needed, in the form of verbal expression is particularly illuminating. While intersubjective metaphors that become conventionalized and de-contextualized are stored in long-term memory and kept there to be used when judged appropriate, individual metaphors employ such aspects that are not conventionally selected; therefore, they require the presence of "information-reach contexts" and are kept in short-term memory. What seems particularly significant, is the claim that the lowest level metaphors, that is those that operate on the level of mental spaces, can be only created by speakers whose mental equipment includes sets of metaphors from higher levels (i.e. employing frames, domains and image schemas).

Kövecses applies his conceptual hierarchy to Lakoff's distinction between "deep" and "superficial" metaphors: the former (significant socially, shaping man's image of the world) emerge on the levels of image-schemas, domains and frames, while the latter (least schematic, created $a d$ hoc in the discourse) operate on the "lowest" level of mental spaces. Significantly, they are "deliberate", i.e. require conscious recourse to "metaphorical thought" (2020: 74). Rather cursory reference to idioms (which are shown to combine different levels and different 
metaphors) and to visual metaphors (a painting by Mark Tansey's picture) signal new vistas open for metaphor research.

Crucially, Kövecses attaches great importance to the role of context in metaphor production and interpretation, and it is to context that he devotes chapter 5 of his monograph. His reference to Langacker's notion of "current discourse space" demonstrates, once again, the commonality of assumptions that underlie ECTM and CL, and the recognition of "relevant context" (evoking Sperber and Wilsons relevance theory) makes it possible to integrate into ECMT the pragmatic notion of relevance. It will be remembered that different types of context as well as their functions had been discussed extensively in Kövecses's earlier work (cf. e.g. Kövecses 2015). In the chapter presently under discussion, particularly relevant is the author's discussion of cognitive processes that cause and condition the emergence of a given metaphor in a given context. Thus the speaker selects metaphor as their means of expression and, very much like in Langacker's model, a particular scene construal. Exposed to various - often mutually incompatible - contexts, they select relevant one(s), and, "being primed by contextual factors", use an appropriate metaphor as the result of their "building a conceptual pathway" (2020: 101). The relevance of this chapter - especially the sections that discuss mutual relations between cognitive processing, contextual factors and metaphor creation - for the analysis of discourses (especially CDA) and texts (especially literature) is an obvious "added value" of the book.

Chapter 6 takes up some of the oppositions signalled earlier in the book: deliberate and non-deliberate use of metaphor, conventional and creative metaphors, long-term and short-term memory storage. They are conducive to what constitutes the core of Kövecses's argument: without integrating the blending theory into the cognitive theory of metaphor it is not possible to describe and to explain the rich and complex variety of metaphors as they appear in the "naturally occurring discourse" (2020: 117). The aim of the argument, therefore, is to demonstrate that mental spaces relate to higher levels of the emergence of metaphors (as presented in earlier chapters) and it is mainly at the level of mental spaces that they are created in natural discourse. At this point, reference to Lakoff"s early notion of "one-shot metaphors" might strengthen the feeling of continuity-cum-development that permeates the entire discussion.

As in earlier chapters, chapter 6 opens wide vistas for research in adjacent fields of discourse analysis, multimodality or literary theory: Kövecses signals possible elaboration of metaphors for rhetorical processes, suggests a rationale for using mixed metaphors or, on the contrary, for construing metaphorically homogeneous discourse, particularly when created for 
specific purposes. As in earlier chapters, the chapter ends with a recapitulation: conceptual integration is more basic than metaphorization, but both are significantly influenced by different types of context. Of the two, metaphorization is more complex than blending: while the latter is operative exclusively on the level of mental spaces, the former can occur at any of the four levels described earlier in the book. While blending operates "online", with blends emerging in short-term memory, cognitive metaphors are based on conventions stored in longterm memory and thus they constitute an "offline" mechanism. Neither of the two processes can be seen as "better" than the other; postulating their integration, Kövecses claims that they can co-exist and gain by complementing each other. This well documented conclusion contributes significantly to the overall value of the book.

Yet, having answered a few pertinent questions, in the concluding chapter 7 the author posits two further fundamental ones: Why is a given metaphor - rather than some other chosen in a given context, and, How can a language user create the particular meaning of a given metaphor and how can the hearer comprehend that meaning? In agreement with intuitions of "common" language users, linguists and translators, he concludes that the level of universality is highest with image-schema formations and diminishes as one moves down the hierarchy to reach the minimum on the level of mental spaces, with the metaphors resulting from "cultural conceptualization" (2020: 164). The chapter ends with a hypothetical model of processes that take place in the mind during the construction of metaphorical meanings. Referred to as "very tentative, informal and naïve", the model seems, nevertheless, well substantiated by the analyses presented earlier in the book. Like most theoreticians, Kövecses does not say much about the reception end of the conceptual path; although its significance is admitted, the question remains to be answered.

Each of the five chapters (2-6) that constitute the main body of the monograph puts forward one of the five questions that any theory of metaphor must face: Can the concrete be understood figuratively? Do metaphors emerge directly or indirectly? How are domains, schemas, frames and spaces (inter)related? Are metaphors conceptual or contextual? Are metaphors "offline" or "online" phenomena? Most importantly, the integration of the theory of blending into CMT - the crucial claim substantiated in the book - results in a comprehensive theory of metaphor which makes it possible to provide some relevant answers. The "added value" is the promise that ECMT provides instruments that can be profitably used by researchers working in other fields, in agreement with today's postulate of transdisciplinarity. Interestingly enough, just recently, support came in the form of a Facebook post by Deepak Chopra, the American propagator of alternative medicine of Indian origin, who advertised 
yoga sessions run by Sarah Platt-Finger, the co-founder of ISHTA Yoga. Chopra wrote: "The element of fire is responsible for the heat, transformation, and motivation within us. When we don't have enough fire, we feel uninspired, unmotivated, and easily depressed. This sequence will offer you simple tools, techniques, and yoga poses to help stoke the fire within, leaving you radiant, glowing, and shining from the inside out" (02.03.2021). INSPIRATION/MOTIVATION IS FIRE; STOKING THE INTERNAL FIRE IS INTERNAL RADIANCE/GLOW/SHINE. In short, metaphors we function by; in seemingly very remote fields.

Last but not least, THE ECMT BOOK IS AN ORGANISM; "organism" is defined by WIKI as "an object whose parts and structures make up a functionally well-toned whole, consisting of many co-ordinated elements." ECMT is an organism, an extremely well-planned and well written monograph. Hence the opening section of each chapter brings an announcement of the contents, and every chapter ends with a recapitulation. This occasionally results in repetitions (viz. the BUILDING metaphor 2020: 64ff., 90), and a great number of references in the text, although informative, sometimes make it difficult to follow smoothly the flow of narrative. However, the gains prevail.

Finally, the list of references is impressive and very useful as a reference source. It brings a comprehensive survey of theoretical works, as well as confirms Kövecses's undisputed expertise: on the list, there are 25 entries of his articles and books on metaphor.

\section{References}

Fauconnier, Gilles (1985) Mental Spaces. Cambridge: Cambridge University Press.

Fauconnier, Gilles, Mark Turner (2002) The Way We Think. Conceptual Blending and the Mind's Hidden Complexities. New York: Basic Books.

Kövecses, Zoltan (2015) Where Metaphors Come from. Reconsidering Context in Metaphor. Oxford: Oxford University Press.

Lakoff, George, Mark Johnson (1980) Metaphors We Live By. Chicago: The University of Chicago Press.

Langacker, Ronald W. (1987) Foundations of Cognitive Grammar. Theoretical Prerequisites. Stanford: Stanford University Press.

Langacker, Ronald W. (2008) Cognitive Grammar. A Basic Introduction. Oxford: Oxford University Press. 
Navarro i Ferrando, Ignasi (2019) Current Approaches to Metaphor Analysis in Discourse. Applications of Cognitive Linguistics [ACL] 39. Berlin, New York: De Gruyter Mouton. Sperber, Dan, Deidre Wilson ([1986] 1995). Relevance: Communication and Cognition. Cambridge Mass.: Blackwell. 